\title{
Arabic version of the Hayling sentence completion test: scale validation, normative data and factors associated with executive functions in a sample of the Lebanese adults
}

Sarah Boutros ${ }^{1 *}$, Emilio El Hachem¹, Joseph Mattar ${ }^{1}$, Souheil Hallit ${ }^{1,2^{*}}$ (D) and Hanna Mattar ${ }^{1,3+}$

\begin{abstract}
Background: This study was conducted for several reasons, primarily because of the lack of an Arabic version of the HSCT that could be beneficial in our clinical practice. Another reason is the need to find potential relationships between various factors with executive functions, especially problematic mobile phone use as suggested by many previous studies, since smartphones have become, nowadays, a daily companion of people from all generations. Thus, it is important to conduct this study in Lebanon to be adapted to the ideas, customs and social behavior of the Lebanese citizens. Hence, the objectives of the current study are to use the Arabic version of the HSCT in healthy community-dwelling Arabic-speaking adults in Lebanon, to check its validity compared to other versions of the test, as well as to identify risk factors that might affect the executive functions in these adults.

Methods: Between August-December 2019, 350 participants were randomly selected. The Arabic version of the HSCT, divided into automatic and inhibition conditions, was used; in each condition, participants' response-time and number of errors committed were recorded.

Results: None of the scale items was removed. For the automatic condition, response-time items converged over one factor $\left(a_{\text {cronbach }}=0.905\right)$ and number of errors converged over seven factors $\left(a_{\text {cronbach }}=0.334\right)$. For the inhibition condition, response-time converged over one factor $\left(a_{\text {cronbach }}=0.943\right)$ and number of errors converged over four factors $\left(a_{\text {cronbach }}=0.728\right)$. Using electricity as a heating method inside the house was significantly associated with a lower response-time, whereas higher problematic mobile phone use was associated with higher response-time. Using wood as a heating system inside the house and higher problematic mobile phone use were associated with higher number of errors, while using Arabian incense (bakhour) inside the house was associated with lower number of errors.

(Continued on next page)
\end{abstract}

\footnotetext{
*Correspondence: boutros.sarah@hotmail.com; souheilhallit@hotmail.com

${ }^{\dagger}$ Souheil Hallit and Hanna Mattar are last co-authors

${ }^{1}$ Faculty of Medicine and Medical Sciences, Holy Spirit University of Kaslik (USEK), Jounieh, Lebanon

Full list of author information is available at the end of the article
}

(C) The Author(s). 2020 Open Access This article is licensed under a Creative Commons Attribution 4.0 International License, which permits use, sharing, adaptation, distribution and reproduction in any medium or format, as long as you give appropriate credit to the original author(s) and the source, provide a link to the Creative Commons licence, and indicate if changes were made. The images or other third party material in this article are included in the article's Creative Commons licence, unless indicated otherwise in a credit line to the material. If material is not included in the article's Creative Commons licence and your intended use is not permitted by statutory regulation or exceeds the permitted use, you will need to obtain permission directly from the copyright holder. To view a copy of this licence, visit http://creativecommons.org/licenses/by/4.0/. The Creative Commons Public Domain Dedication waiver (http://creativecommons.org/publicdomain/zero/1.0/) applies to the data made available in this article, unless otherwise stated in a credit line to the data. 
(Continued from previous page)

Conclusion: We were able to set normative data for the HSCT Arabic version for use in the Lebanese population. Problematic mobile phone use was associated with lower inhibitory control in terms of response-time and errors number.

Keywords: Hayling sentence completion test, Executive functions, Inhibitory control, Normative data, Problematic mobile phone use, Air pollution

\section{Background}

Executive functions (EFs) include the production, preservation, and customization of plans aimed to accomplish the objectives of a given assignment [1]. It includes three main features: (1) inhibitory control, including self-control and interference control, (2) cognitive flexibility, also called mental flexibility, linked to creativity, and (3) working memory $[1,2]$. EFs are crucial skills for mental and physical well-being, school and life success, and for cognitive, social, and psychological growth and evolution [2].

Inhibition represents one of the key skills of EFs. It involves the capacity to control one's attention, behavior, thoughts, and emotions, to suppress a strong internal tendency or external temptation, in order to do what's more relevant or essential [2]. In the absence of inhibition, people would be controlled by their impulses, settled tendencies of thought or behavior, by the environment that pulls them this way or the other [2]. Consequently, inhibition makes each one of us somehow unique, and allows us to proceed and behave deliberately, instead of being unintentional and impulsive creatures of tradition and routine [2].

Inhibition has become crucial in several research domains within psychology and neurology. It is broadly recognized that inhibitory control is a multidimentional procedure encompassing at least three features, as defined by Bayard S et al.: « (1) Prepotent response inhibition (the ability to deliberately suppress dominant, automatic, or prepotent responses), (2) Resistance to distractor interference (the ability to resist interference from distracting information in the external environment), (3) Resistance to proactive interference (the ability to resist the intrusions of irrelevant information, that were once considered relevant, into our memory). » [3].

Taking into account inhibition as a multidetermined construct emphasizes the exigency to invent validated clinical tools for the evaluation of its features [3]. The Hayling Sentence Completion Test (HSCT), originally developed by Burgess \& Shallice, is one of the available tools that evaluate inhibition. It is a measure of prepotent response inhibition that detects frontal lobe dysfunction. In this test, participants hear sentences in which the last word is absent. In the automatic condition, participants are asked to complete sentences correctly (i.e., by a word solidly related to the sentence), reflecting the initiation of a semantically supported automatic response. In the inhibition condition, participants are asked to restrain themselves from saying the cueing word, and to complete the sentence with a totally unrelated word. To perform this task appropriately, participants have to inhibit the related word and its semantic associates [4].

To the best of the author's knowledge, only five validated languages have been published for the HSCT in adults and elderly people: (1) English [5], (2) Spanish [6], (3) French [3], (4) Italian [7], and (5) Swedish [8]. There are no HSCT normative data for the Arabic speakers to date, so it cannot be used in Arabic-speaking clinical practice and research groups not only in Lebanon but also in all the 25 Arabic speaking countries around the world. Being a very interesting neuropsychological tool, because it is one of the few tests measuring orbitofrontal dysfunction, emphasizes the need to this Arabic version. Therefore, this study intends to create an Arabic version of the HSCT that is standardized to the linguistic and cultural realities of the Lebanese population.

EFs are negatively influenced by many factors, among which cognitive aging, which usually weakens executive functioning [9], and low family socioeconomic status (SES), which predicts a worse performance on tasks that evaluate them [10]. In contrast, high educational levels improve scores in the HSCT [3], and multilingualism is associated with greater amount of controlled attention and inhibitory control, and can play a crucial role in protecting against the deterioration of executive functions with aging by helping to achieve cognitive reserve [11]. Furthermore, there is a positive correlation between healthy diet (e.g. whole grains, fish, fruits and/or vegetables) and executive functions, unlike unhealthy diet (e.g. fast food, sweetened beverages and red meat) that is associated with a decrease in executive functioning [12]. Moreover, a meta-analysis revealed a wide EFs deficit in overweight participants compared to healthy weight controls, specifically a deficit in inhibition and working memory in overweight participants [13], while better physical fitness is shown to improve cognitive flexibility [14]. On another note, a negative correlation was exhibited between EFs and constant exposure to polluted air and traffic noise [15].

Studies concerning the relationship between long-term mobile phone use and EFs are equivocal. Previous 
findings showed no evidence of a harmful effect of smartphone use on cognitive functioning. Instead, it suggests there could possibly be a favorable effect of phone use on cognitive performance and executive functioning, but the results of longitudinal analyses were confusing [16]. Another study indicated that a daily exposure (2 h/ day for 4 weeks) to electromagnetic fields (EMF) emitted by mobile phones (MP) has no effect on executive function [17]. One more research done in 2017 by Hayashi Y et al. reveals that participants who constantly text while driving have low levels of executive function and high levels of impulsivity [18].

Some studies show a relationship between the use of some medications and the increase or decline in executive functions; proton pump inhibitors (PPI's) have varying degrees of influence on different cognitive domains and have associations with Alzheimer's Disease (AD) [19]. On another note, Angiotensin I receptor blockers (ARBs) improve memory and executive function in comparison to other antihypertensive drugs, and it attenuates the decline of cognition over time [20]. Moreover, aspirin use is also associated with a preventive effect against cognitive decline, particularly in people at risk for developing dementia [21].

This study was conducted for several reasons, primarily because of the lack of an Arabic version of the HSCT that could be beneficial in our clinical practice. Another reason is the need to find potential relationships between various factors with executive functions, especially problematic mobile phone use as suggested by many previous studies, since smartphones have become, nowadays, a daily companion of people from all generations. Thus, it is important to conduct this study in Lebanon to be adapted to the ideas, customs and social behavior of the Lebanese citizens. Hence, the objectives of the current study are to use the Arabic version of the HSCT in healthy community-dwelling Arabic-speaking adults in Lebanon, to check its validity compared to other versions of the test, as well as to identify risk factors that might affect the executive functions in these adults.

\section{Methods}

\section{Study design}

This study was conducted between August and December 2019. Participants were randomly chosen from the general population across Lebanon by invitations distributed by the municipality of each village from all Lebanese governorates and there were no compensations or rewards to any participant. Individuals included in this study were aged above 18 years old, having no known history of neurological or psychological impairment. Excluded participants were those expected to have abnormal performances on the HSCT, which have been described in a wide variety of neurological, psychiatric, and neurodevelopmental conditions, such as Alzheimer's disease and mild cognitive impairment [22-24], brain traumatic injury [25], cerebrovascular accidents [26], Parkinson's disease [27], amyotrophic later sclerosis [28], frontotemporal dementia [28], schizophrenia [29], bipolar disorder [30], and autism spectrum disorder [31]. Participants aged above 55 years old [32] underwent a mini mental state examination (MMSE); those obtaining a score of 24 or more were included in the study [33].

\section{Minimal sample size calculation}

According to Comrey and Lee [34], a minimal sample of $5-10$ observations is needed per item of the scale in order to validate a scale. Therefore, a minimum of 300 participants was needed for adequate statistical power, since the assessment of the automatic and inhibition conditions included 15 items each.

\section{Instruments}

Data was collected via a personal interview, and participants were tested with only one examiner in a quiet office. All sections of the questionnaire need approximately 10 min to be completed. The first section assesses the sociodemographic characteristics, including age, gender, region, the number of rooms in the household and the number of persons living in it (both variables used to calculate the household crowding index), the level of education, the number of mastered languages, the monthly income, and the medical history and chronic treatments.

The second section evaluates the diet of each participant, taking into consideration vegetables, fruits, dairy products, breakfast, eating 5 meals per day, sweets consumption, red meat, beverages, and fast food. Each variable is scored between 1 and 5 to get a minimum score of 9 and a maximum score of 45; higher scores indicate a healthier diet. This scale was based on the constituents of the DASH diet (Dietry Approaches to Stop Hypertension) [35].

The third section is the Arabic translation of the short form of International Physical Activity Questionnaire (IPAQ) [36] that asks about three specific types of activities: walking, moderate-intensity activities, and vigorousintensity activities. Then participants are classified to have low, moderate, or high physical activity.

To be classified as 'moderate', participants should match one of the following:

a) $\geq 3$ days of vigorous-intensity activity for a minimum of 20 min per day.

OR

b) $\geq 5$ days of moderate-intensity activity and/or walking for a minimum of $30 \mathrm{~min}$ per day. 
OR

c) $\geq 5$ days of any combination of walking, moderateintensity or vigorous intensity activities, achieving at least a total physical activity of $600 \mathrm{~min} /$ week.

To be classified as 'high', participants should match one of the following:

a) vigorous-intensity activity $\geq 3$ days, achieving at least $1500 \mathrm{~min} /$ week.

\section{OR}

b) $\geq 7$ days of any combination of walking, moderateintensity or vigorous-intensity activities of at least $3000 \mathrm{~min} /$ week.

Participants who did not meet the above criteria were considered to have a 'low' physical activity level [36].

The fourth section assesses the exposure to polluted air; participants are asked about the environment where they live, the heating system used (wood, gas, electricity), if they are living or working next to factories (wood, plastic, chemicals ...) or power stations, and their exposure to cigarette smoking.

The fifth section represents the Arabic translation of the Short Version of the Problematic Mobile Phone Use Questionnaire (PMPUQ-SV), containing 15 items that are scored from 1 ('I strongly agree') to 4 ('I strongly disagree'), except for 8 items that are reversely scored. Overall scores range from 15 to 60, with higher scores indicating a higher risk for problematic mobile phone use [37].

\section{The Hayling sentence completion test}

The HSCT was translated to Arabic from the French version [3] because it is the only version having sentences likely to be translated to Arabic without big differences or changes and it was adapted to the linguistic and cultural realities of the Lebanese population so the sentences would be clear and potentially have only one answer. It is because of the fact that Lebanon was under the French Mandate until 1943 and thus French became the prevalent non-Arabic spoken language by Lebanese citizens until recently, which means that a large percentage of the population likely speak Arabic and French, resulting in more familiarity with its linguistics characteristics.

The A-HSCT consists of two conditions (automatic and inhibition), for which two different groups of 15 sentences are given. In both conditions, the interviewer reads out loud the unfinished sentences, and the participant has to complete each sentence with one word [4].

\section{Automatic condition}

The participants are requested to give a word that is related to the beginning of the sentence, and should do so as quickly as possible. For example, "He mailed the letter without a. .. (participant says) stamp." Time latency in automatic condition measures the participant's rapidity in initiating an automatic response. According to the scoring system, three error points are scored when participants provide an incorrect word, one point when the answer is semantically related to the sentence, and no error point if the correct word is given. Higher error score corresponds to a lower performance [4].

\section{Inhibition condition}

The participants are requested to complete the sentence as fast as they can with a word that is completely unlinked to it, which makes no sense at all in the context of the sentence. For example, "The captain wanted to stay with the sinking. .. (participant says) apple." If at any time during this condition the participant completes the sentence correctly instead of using an unrelated word, s/he is told that the word is too linked to the sentence and is retold the task instructions. Time latency in inhibition condition gives information about the time needed to inhibit the correct response and find an incorrect one [4]. According to the scoring system, three points are given when the sentence is completed with the answer that fits with it. One point is given when a participant gives an antonym, a semantically related word, or a word that makes a vague reference to the sentence. Participants receive zero points when a totally unrelated word is provided. A higher error score indicates a lower performance [4].

The total time to complete both conditions of the AHSCT was approximately $5 \mathrm{~min}$. The automatic condition was tested prior to the inhibition section. Two practice sentences were initially presented prior to each condition. Time of response latency was measured and collected using a stopwatch in both conditions; the timing began soon after the tester finished the sentence, and was stopped soon after the participant began their answer. Response latencies were recorded in whole second units and were not rounded up. For instance, a time between 0 and 0.99 was scored as 0 . An average response latency score of all the individual's latencies for each condition was then computed based on all responses, including errors. No time limit was given for responding. Errors were also scored to evaluate the efficacy of the strategy elaborated by the participant to give an incorrect response [4]. The score calculation method for the both conditions is mentioned in the associated appendix.

All sections of the questionnaire were translated to Arabic by a certified translator, then the translation was 
retranslated to its original language by another specialist. Upon fulfillment of this procedure, the translators compared the versions of every scale to determine whether the variables had the same meaning. No major incompatibilities were found between the two versions for all scales; they were resolved by consensus.

\section{Statistical analysis}

Statistical Package for Social Science (SPSS) version 23 was used for the statistical analyses. Two different methods were used to confirm the HSCT questionnaire construct validity. A principal component analysis, using a promax rotation since the questions of the scales were correlated, was conducted in order to validate the automatic and inhibition parts of the HSCT. Adequacy of the sample was confirmed through the Kaiser-MeyerOlkin (KMO) index, Bartlett's Chi-square test of sphericity and scree plot. Factors with an Eigenvalue higher than one were retained. Second, a confirmatory factor analysis was carried out on Sample 2. To assess the structure of the instrument the maximum likelihood method for discrepancy function was used. Several goodness-of-fit indicators were reported: Relative chi square $(\times 2 / d f)$, Root Mean Square Error of Approximation (RMSEA), Goodness of Fit Index (GFI) and the Adjusted Goodness of Fit Index (AGFI). The index of goodness of fit was calculated by the value of $\times 2$ divided by the degrees of freedom $(\times 2 / \mathrm{df})$ (cut-off values $<2-5$ ). The RMSEA tests the fit of the model to the covariance matrix. As a guideline, values of $<0.05$ indicate a close fit and values below 0.11 an acceptable fit. The GFI and AGFI are chi-square-based calculations independent of degrees of freedom. The recommended thresholds for acceptable values are $\geq 0.90$ [38]. The Student $t$-test was used to compare two means, whereas the Pearson correlation was used to study the association between two continuous variables. Multivariable linear regression models were done to explore factors associated with the response-time and the number of errors taken as dependent variables and taking all variables that showed a $p<0.05$ in the bivariate analysis as independent variables. A $p<0.05$ was considered significant. Reliability was assessed using Cronbach's alpha.

\section{Results}

Out of 364 participants approached, 350 (96.15\%) accepted to enroll in this study and completed the HSCT in approximately $5 \mathrm{~min}$. The mean age of the participants was 45.72 years, with 177 (50.6\%) of them being females. Other sociodemographic and characteristics of the participants are summarized in Tables 1 and 2. In the automatic condition of the HSCT, 346 participants (98.9\%) made $\leq 2$ errors and 333 individuals (96\%)
Table 1 Sociodemographic characteristics of the participants

\begin{tabular}{|c|c|}
\hline Variable & Mean \pm SD \\
\hline Age (in years) & $45.72 \pm 21.15$ \\
\hline Body Mass Index $\left(\mathrm{kg} / \mathrm{m}^{2}\right)$ & $24.64 \pm 3.82$ \\
\hline Years of study & $16.49 \pm 5.79$ \\
\hline House crowding index & $0.99 \pm 0.45$ \\
\hline Problematic mobile phone use & $31.04 \pm 10.84$ \\
\hline \multirow[t]{2}{*}{ Total food score } & $34.65 \pm 4.53$ \\
\hline & N (\%) \\
\hline \multicolumn{2}{|l|}{ Governorate } \\
\hline Beirut & $42(12.0 \%)$ \\
\hline Mount Lebanon & $66(18.9 \%)$ \\
\hline North & $106(30.3 \%)$ \\
\hline South & $67(19.1 \%)$ \\
\hline Bekaa & $69(19.7 \%)$ \\
\hline \multicolumn{2}{|c|}{ Classification executive function- time } \\
\hline Pathologic & $17(4.9 \%)$ \\
\hline Limit & $45(12.9 \%)$ \\
\hline Normal & $221(63.5 \%)$ \\
\hline Superior & $55(15.8 \%)$ \\
\hline Very superior & $10(2.9 \%)$ \\
\hline \multicolumn{2}{|c|}{ Classification executive function- number of errors } \\
\hline Pathologic & $16(4.6 \%)$ \\
\hline Limit & $49(14.0 \%)$ \\
\hline Normal & $205(58.7 \%)$ \\
\hline Superior & $72(20.6 \%)$ \\
\hline Very superior & $7(2.0 \%)$ \\
\hline \multicolumn{2}{|l|}{ Categories of the diet levels } \\
\hline Not healthy & $2(0.6 \%)$ \\
\hline Moderately healthy & $16(4.6 \%)$ \\
\hline Healthy & $168(48.0 \%)$ \\
\hline Very healthy & 164 (6.9\%) \\
\hline
\end{tabular}

responded in $\leq 2$ seconds. Accordingly, no additional calculations were conducted on these scores.

All the following results will be concerning the second part of the HSCT (The inhibition condition). The results of the inhibiton condition of the HSCT showed that 221 $(63.5 \%)$ of the participants had normal response-time, whereas $205(58.7 \%)$ had normal scores in terms of number of errors.

The norms for participants classification and the calculation method of the test score are summarized in Table 3.

\section{Validation of the HSCT scale Exploratory factor analysis}

The principal component analysis (PCA) for the automatic and inhibition response-time and number of 
Table 2 Number of participants according to the different age ranges

\begin{tabular}{ll}
\hline Age range & Number of participants \\
\hline $18-30$ & 132 \\
$31-40$ & 26 \\
$41-50$ & 40 \\
$51-60$ & 67 \\
$61-70$ & 32 \\
$71-80$ & 30 \\
$81-90$ & 21 \\
$91-100$ & 2 \\
\hline
\end{tabular}

errors questions was run over sample $1(n=250)$. None of the automatic condition response-time items was removed and converged over one factor (variance explained $=47.92 \% ; \mathrm{KMO}=0.936 ;$ Bartlett sphericity $p<$ $\left.0.001 ; \alpha_{\text {Cronbach }}=0.905\right)$. Two items (items 3 and 12) of the automatic condition number of errors items were removed since all participants had the same answer. The items converged over seven factors (variance explained = $71.41 \% ; \quad \mathrm{KMO}=0.464 ; \quad$ Bartlett sphericity $p<0.001$; $\left.\alpha_{\text {Cronbach }}=0.334\right)$. None of the inhibition condition response-time items was removed and converged over one factor (variance explained $=56.59 \% ; \mathrm{KMO}=0.962$; Bartlett sphericity $\left.p<0.001 ; \alpha_{\text {Cronbach }}=0.943\right)$. One item (item 12) of the inhibitory condition number of errors items was removed since all participants had the same answer. The items converged over four factors (variance explained $=49.57 \%$; $\mathrm{KMO}=0.797$; Bartlett sphericity $p<$ $\left.0.001 ; \alpha_{\text {Cronbach }}=0.728\right)($ Table 4$)$.

\section{Confirmatory factor analysis on sample 2}

A confirmatory factor analysis was run on sample $2(n=$ 100), using the structure obtained in Sample 1. The following results were obtained: the Maximum Likelihood Chi-Square $=642.6$ and Degrees of Freedom $=270$, which gave an $\times 2 / d f=2.38$. For non-centrality fit indices, the

Table 3 Hayling sentence completion test scores calculation [3]

A first transformation of results (response time and number of errors for each participant) via $\left(\mathrm{LOG}_{10}+1\right) \rightarrow \mathrm{A}$ for response time and $\mathrm{B}$ for number of errors.

Second transformation using formulas mentioned in the French version: a. Response time: $\hat{y}=\mathrm{A}+(0.002 \mathrm{x}$ age $)-(0.008 \mathrm{x}$ education)

b. Number of errors: $\hat{y}=B+(0.003$ xage $)$ - (0.02x education)

$\mathrm{Z}$ score calculation using the second transformation

Classification depending on Zscores:

a. $\leq-1.65$ pathologic

b. $[-1.64 \rightarrow-1]$ limit;

c. $[-0.99 \rightarrow+0.99]$ normal;

d. $[+1 \rightarrow+1.64]$ superior

e. $\geq+1.65$ very superior.
Steiger-Lind RMSEA was on 0.12 [0.108-0.139]. Moreover, the Joreskog GFI equaled 0.767 and AGFI equaled 0.711 .

\section{Bivariate analysis}

The results of the bivariate analysis of factors associated with the response time showed that diabetic patients (0.42 vs 0.15$)$, those with hypertension $(-0.42$ vs 0.20$)$, those with cardiac diseases ( -0.53 vs 0.08$)$, those taking aspirin ( -0.58 vs 0.11 ), and those who use electricity as a heating system in the house $(-0.25 \mathrm{vs} 0.21)$ had significantly lower response-time compared to the opposite groups. In terms of number of errors, the results showed that those who do not use wood as a heating system in the house ( -0.18 vs 0.29$)$ and those who use bakhour (Arabian incense) ( -0.25 vs 0.16$)$ had significantly lower number of errors (better performance) compared to the opposite groups (Table 5).

Higher age was significantly associated with lower response-time, whereas higher problematic mobile phone use was significantly associated with higher response-time and higher number of errors (worse performance) (Table 6).

\section{Multivariable analysis}

The results of a first linear regression, taking the response-time as the dependent variable, showed that using electricity as a heating method inside the house $(B=-0.3)$ was significantly associated with lower response-time (better performance), whereas a higher problematic mobile phone use $(B=0.03)$ was significantly associated with higher response-time (worse performance) (Table 7, Model 1).

The results of a second linear regression, taking the number of errors as the dependent variable, showed that using wood as a heating system inside the house $(B=$ $0.41)$ and higher problematic mobile phone use $(B=$ 0.02 ) were significantly associated with higher number of errors (worse performance), whereas using Arabian incense (bakhour) inside the house $(B=-0.29)$ was significantly associated with a lower number of errors (better performance) (Table 7, Model 2).

Since sociodemographic variables didn't remain in the final model, the multivariable analysis results were considered adjusted over them (age, sex,educational level, number of rooms in the household).

\section{Discussion}

To the best of the authors' knowledge, this is the first study to set normative data for the Hayling test in Arabic, and to assess factors associated with executive functioning among a sample of the Lebanese population. These results constitute the exclusive source of norms for this test in the Lebanese population. 
Table 4 Principal component analysis results using the promax rotation

\begin{tabular}{lr}
\hline Item number & Factor \\
\hline Scale 1: Automatic condition \\
12 & 0.818 \\
7 & 0.810 \\
1 & 0.732 \\
15 & 0.731 \\
11 & 0.728 \\
5 & 0.716 \\
10 & 0.716 \\
4 & 0.686 \\
8 & 0.682 \\
9 & 0.676 \\
14 & 0.635 \\
3 & 0.621 \\
13 & 0.614 \\
2 & 0.598 \\
6 & 0.569
\end{tabular}

Scale 2: Automatic condition number of errors.

5

7

6

15

14

9

13

2

8

10

11

Scale 3: Inhibitory condition response time.

$\begin{array}{ll}12 & 0.823 \\ 6 & 0.811 \\ 3 & 0.803 \\ 4 & 0.779 \\ 13 & 0.770 \\ 11 & 0.769 \\ 15 & 0.762 \\ 5 & 0.758 \\ 2 & 0.757 \\ 7 & 0.750 \\ 14 & 0.750 \\ 10 & 0.738 \\ 9 & 0.731\end{array}$

803

0.779

769

762

.750

750

0.731
0.579

0.502

0.728

0.709

0.709

0.729

0.685

0.816 
Table 4 Principal component analysis results using the promax rotation (Continued)

\begin{tabular}{|c|c|c|c|c|c|c|c|}
\hline Item number & Factor 1 & Factor 2 & Factor 3 & Factor 4 & Factor 5 & Factor 6 & Factor 7 \\
\hline 8 & 0.666 & & & & & & \\
\hline 1 & 0.586 & & & & & & \\
\hline \multicolumn{8}{|c|}{ Scale 4: Inhibitory condition number of errors. } \\
\hline 11 & 0.744 & & & & & & \\
\hline 9 & 0.713 & & & & & & \\
\hline 10 & 0.669 & & & & & & \\
\hline 8 & 0.459 & & & & & & \\
\hline 6 & & 0.791 & & & & & \\
\hline 1 & & 0.660 & & & & & \\
\hline 5 & & 0.442 & & & & & \\
\hline 3 & & & 0.746 & & & & \\
\hline 2 & & & 0.718 & & & & \\
\hline 7 & & & 0.449 & & & & \\
\hline 4 & & & 0.425 & & & & \\
\hline 14 & & & & 0.705 & & & \\
\hline 13 & & & & 0.665 & & & \\
\hline 15 & & & & 0.528 & & & \\
\hline
\end{tabular}

\section{Validation of the A-HSCT}

In this current study, the preliminary results suggest the validity of the Arabic version of the Hayling Sentence Completion Test (A-HSCT) designed precisely for the Lebanese population. Results delivered primary evidence supporting the accuracy and validity of this test as a clinical instrument to measure prepotent response inhibition in Lebanese adults having a wide range of neurological or psychological disorders. In this study, all the sentences were translated to Arabic to be adapted to the Lebanese culture and habits. Consequently, the Lebanese protocol revealed that the new set of sentences of the HSCT preserved strong accuracy, based on Cronbach's alpha.

As compared to the Spanish version where the Cronbach's alpha was 0.864 for the response-time in the automatic condition, in the current study, a slightly higher value of 0.905 was obtained. In addition, Cronbach's alpha for the response time in the inhibition condition in the Spanish version was 0.797 , while in this version, it is considerably higher with a value of 0.943 .

The Cronbach's alpha for the number of errors in the inhibition condition of the Spanish version was 0.839. In this Arabic version a slightly smaller value of 0.728 was acquired. In this Arabic version, Cronbach's alpha for the number of errors in the automatic condition is 0.334 (where items were converged over eight factors). However, the one for the Spanish version in this same condition was not mentioned [6].

\section{Factors associated with executive functions}

\section{Problematic mobile phone use}

Many studies investigating the effect of Electromagnetic Field (EMF) exposure in mobile phone users, which are waves emitted by mobile phones, report a slower electroencephalograhic (EEG) activity in these individuals, along with a hypoactivation of a major participant in the regulation of executive functions, the Anterior Cingulated Cortex (ACC). Thus, worse performance on tasks requiring executive functions is associated with long-term mobile phone use $[16,18]$. In addition, a research studying the effect of EMF on the neurodevelopment of neonates and children highlights the importance of epigenetic mechanisms that can lead to altered attention, memory and cognition [39]. This goes hand in hand with the results of our study, which showed an increase in both response-time and number of errors in the inhibition condition of the Arabic version of the HSCT for individuals with problematic mobile phone use, indicating a poorer performance. On the other hand, some studies contradict these results, suggesting an enhancement in executive functions among mobile phone users. However, most of these studies reported limitations to their results $[17,40]$, emphasizing on the need to conduct further longitudinal studies to clarify the true effect of mobile phone use on executive functions.

\section{Heating system and air pollution}

The results of our study concerning the effects of outdoor air pollution on executive functions were 
Table 5 Bivariate analysis of factors associated with the response time and number of errors

\begin{tabular}{|c|c|c|}
\hline Variable & Response time & Number of errors \\
\hline \multicolumn{3}{|c|}{ Diabetes Mellitus } \\
\hline No & $0.15 \pm 0.98$ & $0.23 \pm 1.02$ \\
\hline Yes & $-0.42 \pm 0.93$ & $-0.06 \pm 0.95$ \\
\hline P & $<0.001$ & 0.301 \\
\hline \multicolumn{3}{|c|}{ Hypertension } \\
\hline No & $0.20 \pm 0.97$ & $0.07 \pm 1.05$ \\
\hline Yes & $-0.42 \pm 0.94$ & $-0.13 \pm 0.88$ \\
\hline P & $<0.001$ & 0.039 \\
\hline \multicolumn{3}{|c|}{ Cardiac diseases } \\
\hline No & $0.08 \pm 0.98$ & $0.02 \pm 1.03$ \\
\hline Yes & $-0.53 \pm 1.01$ & $-0.15 \pm 0.74$ \\
\hline P & $<0.001$ & 0.132 \\
\hline \multicolumn{3}{|c|}{ Proton pump inhibitors } \\
\hline No & $0.06 \pm 1.01$ & $0.04 \pm 1.04$ \\
\hline Yes & $-0.27 \pm 0.93$ & $-0.20 \pm 0.75$ \\
\hline P & 0.024 & 0.039 \\
\hline \multicolumn{3}{|l|}{ Aspirin } \\
\hline No & $0.11 \pm 0.97$ & $0.05 \pm 1.03$ \\
\hline Yes & $-0.58 \pm 0.94$ & $-0.26 \pm 0.79$ \\
\hline P & $<0.001$ & 0.015 \\
\hline \multicolumn{3}{|c|}{ Heating inside the house- wood } \\
\hline No & $-0.004 \pm 1.01$ & $-0.18 \pm 1.04$ \\
\hline Yes & $0.007 \pm 0.98$ & $0.29 \pm 0.86$ \\
\hline$P$ & 0.796 & $<0.001$ \\
\hline \multicolumn{3}{|c|}{ Heating inside the house- Electricity } \\
\hline No & $0.21 \pm 0.94$ & $0.08 \pm 0.94$ \\
\hline Yes & $-0.25 \pm 1.01$ & $-0.09 \pm 1.06$ \\
\hline P & $<0.001$ & 0.111 \\
\hline \multicolumn{3}{|l|}{ Bakhour } \\
\hline No & $-0.04 \pm 0.98$ & $0.16 \pm 0.95$ \\
\hline Yes & $0.06 \pm 1.03$ & $-0.25 \pm 1.03$ \\
\hline$P$ & 0.484 & $<0.001$ \\
\hline \multicolumn{3}{|c|}{ Living in a polluted area } \\
\hline No & $0.07 \pm 0.88$ & $-0.36 \pm 1.09$ \\
\hline Yes & $-0.003 \pm 1.03$ & $0.10 \pm 0.95$ \\
\hline P & 0.789 & 0.003 \\
\hline \multicolumn{3}{|c|}{ Exposed to sand and dust soil } \\
\hline No & $-0.75 \pm 0.62$ & $-0.15 \pm 1.07$ \\
\hline Yes & $-0.16 \pm 1.15$ & $-0.05 \pm 0.91$ \\
\hline P & 0.028 & 0.474 \\
\hline \multicolumn{3}{|c|}{ Factories (usines) } \\
\hline No & $0.003 \pm 0.99$ & $0.04 \pm 0.99$ \\
\hline Yes & $-0.05 \pm 1.17$ & $-0.66 \pm 0.78$ \\
\hline$P$ & 0.692 & 0.002 \\
\hline
\end{tabular}

Numbers in bold indicate significant $p$-values
Table 6 Bivariate analysis of continuous variables associated with the response time and number of errors

\begin{tabular}{lll}
\hline Variable & $\begin{array}{l}\text { Response } \\
\text { time }\end{array}$ & $\begin{array}{l}\text { Number of } \\
\text { errors }\end{array}$ \\
\hline Age & $-0.345^{\mathrm{a}}$ & -0.053 \\
Body Mass Index & $-0.153^{\mathrm{b}}$ & -0.06 \\
Number of years of study & $0.145^{\mathrm{b}}$ & -0.079 \\
Total food score & -0.052 & $0.139^{\mathrm{b}}$ \\
Number of smokers in the house & $-0.135^{\mathrm{b}}$ & -0.077 \\
$\begin{array}{l}\text { Problematic mobile phone use } \\
\text { score }\end{array}$ & $0.401^{\mathrm{a}}$ & $0.215^{\mathrm{a}}$ \\
Household crowding index & $-0.115^{\mathrm{c}}$ & 0.012 \\
\hline
\end{tabular}

${ }^{\mathrm{a}} p<0.001 ;{ }^{\mathrm{b}} p<0.01 ;{ }^{\mathrm{c}} p<0.05$

inconclusive. However, indoor air pollution attributed to the use of wood burning as a heating system is linked to a lower performance of the interviewed participants, particularly in the number of errors committed in the inhibition condition of the A-HSCT. This negative correlation could be due to the exposure of individuals to air pollutants resulting from wood burning chemical reactions, as mentioned in various studies, particularly $\mathrm{CO} 2$ inhalation that is anxiogenic and deleterious for executive functions $[41,42]$. In contrast, participants who use electricity as a source of heating in their households performed better in terms of response-time in the inhibition condition of our test, which goes in line with the result mentioned above.

On another note, Bakhour is a widespread spiritual practice in the Middle East region, composed of a vast range of chemical compounds and metals. Opposed to the upstated results concerning indoor air pollution, the use of Arabian incense was associated with a decreased number of errors in the inhibition condition committed during the A-HSCT. A hypothesis may arise, concerning the potential attribution to the spirituality inferred by the use of Bakhour among the participants, which is the subject of many studies that elaborate the benefits of spirituality on executive functions, and its capacity in attenuating the severity of depression [43].

\section{Other factors}

In the bivariate analysis, participants who are older, use aspirin, have cardiac diseases, diabetes, or hypertension exhibited better performance in terms of response-time in the inhibition condition of the A-HSCT. These results contradict the literature that underlines the negative correlation between executive functions and aging [9]. However, they could be explained by the fact that many of the elderly participants reported taking metformin, aspirin, atorvastatin, and angiotensin converting enzyme inhibitors (ACEi) or ARBs, which, when taken as a combination, could potentiate the anti-oxidant effect of each 
Table 7 Multivariable analysis

\begin{tabular}{|c|c|c|c|c|c|}
\hline \multirow{2}{*}{$\begin{array}{l}\text { Variable } \\
\text { Model 1: L }\end{array}$} & \multirow{2}{*}{$\begin{array}{l}\text { Unstandardized Beta } \\
\text { time as the dependent }\end{array}$} & \multirow{2}{*}{$\begin{array}{l}\text { Standardized Beta } \\
\text { iable. }\end{array}$} & \multirow[t]{2}{*}{$p$} & \multicolumn{2}{|c|}{ 95\% Confidence Interval } \\
\hline & & & & & \\
\hline Heating in the house- Electricity (yes vs no*) & -0.30 & -0.15 & 0.003 & -0.50 & -0.10 \\
\hline Problematic mobile phone use & 0.03 & 0.35 & $<0.001$ & 0.02 & 0.04 \\
\hline \multicolumn{6}{|c|}{ Model 2: Linear regression taking the number of errors as the dependent variable. } \\
\hline Heating in the house- Wood (yes vs no*) & 0.41 & 0.20 & $<0.001$ & 0.20 & 0.63 \\
\hline Bakhour use in the house (yes vs no*) & -0.29 & -0.14 & 0.007 & -0.50 & -0.08 \\
\hline Problematic mobile phone use & 0.02 & 0.21 & $<0.001$ & 0.01 & 0.03 \\
\hline
\end{tabular}

"Reference group

drug, enhancing their neuroprotective effects on the hippocampus [44].

\section{Clinical implications}

The A-HSCT is a clinical tool that measures inhibitory control as part of executive functions, reflecting mainly frontal cortex function. We aim that this version of the HSCT would be used, after its clinical validation, in patients with many neurological or psychological disorders to follow them up throughout the years, and to detect amelioration or deterioration of their scores. Moreover, by comparing the patients' scores, clinicians can detect the efficacy of their treatment and medications.

\section{Limitations}

Our study is based on the questionnaire that was applied on the participants during an interview. Thus, some of these participants might have felt pressured or shy while being interviewed, leading them to give wrong answers or to perform poorly in the given tasks. An information bias is also possible because of potential misunderstanding. The possibility of recall bias might be considered due to the need of the participants to remember activities of their daily lives. The effect of the recall bias could be differential and may lead to the overestimation or underestimation of effects for some factors, hence the need for prospective studies that overthrow the recall bias and can show more significant and precise association between problematic mobile phone use and inhibitory control as part of executive functions. The extent of exposure to different air pollutants was subjectively evaluated by each participant. Unfortunately, there were no possible means to measure the quantity and time of exposure to each air pollutant. In future studies a bigger sample is needed to reinforce the correlation between problematic mobile phone use and the deterioration of executive functions precisely inhibition. Unluckily, there was no test-retest reliability and no comparison with other measures of inhibition or any other test of executive function. Not to forget that, use of a smaller patient group with inhibitory deficit would have been informative, as this would have clarified whether this translation of the Hayling test could be used to identify participants with known inhibitory deficits. It would be better to take these limitations into consideration in the future studies to obtain more precise and reliable results.

\section{Conclusion}

The preliminary results suggest that the Arabic version of the Hayling Sentence Completion Test is now a valid tool that can be used by clinicians to measure response inhibition in adults and elderly patients in the Lebanese population. These results could suggest a potential association between many factors and inhibitory control. The most significant was problematic mobile phone use and the deterioration of executive functions, mainly inhibitory control, in terms of both response-time and number of errors in the A-HSCT. To the best of the author's knowledge, the present study is the first to create normative data for the A-HSCT in the Lebanese population.

Furthermore, it should be noted that additional studies are needed to prove a possible harmful effect of mobile phone use on frontal cortex, since it became a primarily used feature in our daily life.

\section{Abbreviations}

HSCT: Hayling Sentence Completion Test; EF: Executive functions; SES: Socioeconomic status; EMF: Electromagnetic fields; MP: Mobile phones; PPI: Proton pump inhibitors; AD: Alzheimer's Disease; ARB: Angiotensin I receptor blockers; DASH: Dietry Approaches to Stop Hypertension; IPAQ: International Physical Activity Questionnaire; PMPUQ-SV: Problematic Mobile Phone Use Questionnaire; SPSS: Statistical Package for Social Science; KMO: Kaiser-Meyer-Olkin; EEG: Electroencephalograhic; ACC: Anterior Cingulated Cortex; ACEi: Angiotensin converting enzyme inhibitors; PCA: Principal Component Analysis

\section{Acknowledgments}

We express our gratitude to the participants who donated their time in completing the questionnaires. We would also like to thank the research assistants and the investigators who contributed in the data collection, and the staff experts who helped building this study.

\section{Authors' contributions}

SB was responsible for the data collection and designed the study; SB drafted the manuscript; $\mathrm{SH}$ carried out the analysis and interpreted the results, assisted in drafting and reviewing the manuscript; EAH and JM helped in the drafting the paper. $\mathrm{SH}$ and HM were the project supervisors. All authors reviewed the final manuscript and gave their consent. The author(s) read and approved the final manuscript. 


\section{Funding}

None.

\section{Availability of data and materials}

All data generated or analyzed during this study are not publicly available to maintain the privacy of the individuals' identities. The dataset supporting the conclusions is available upon request to the corresponding author.

\section{Ethics approval and consent to participate}

The study protocol was approved by the Psychiatric Hospital of the Cross ethics committee (HPC-015-2019). A written informed consent was obtained from each participant.

\section{Consent for publication}

Not applicable.

\section{Competing interests}

The authors have nothing to disclose.

\section{Author details}

${ }^{1}$ Faculty of Medicine and Medical Sciences, Holy Spirit University of Kaslik (USEK), Jounieh, Lebanon. ${ }^{2}$ INSPECT-LB: Institut National de Santé Publique, Épidémiologie Clinique et Toxicologie-Liban, Beirut, Lebanon. ${ }^{3}$ Department of Neurology, Notre Dame des Secours University Hospital, Byblos, Lebanon.

\section{Received: 18 August 2020 Accepted: 3 December 2020}

\section{Published online: 11 December 2020}

\section{References}

1. Barkley RA. Executive functions: What they are, how they work, and why they evolved. NY: Guilford Press; 2012.

2. Sira CS, Mateer CA. Executive function; 2014

3. Bayard S, Gely-Nargeot MC, Raffard S, Guerdoux-Ninot E, Kamara E, GrosBalthazard F, College des Psychologues Cliniciens specialises en Neuropsychologie du Languedoc, Roussillon. French version of the hayling sentence completion test, part i: normative data and guidelines for error scoring. Arch Clin Neuropsychol. 2017;32(5):585-91. https://doi.org/10.1093/ arclin/acx010

4. Burgess PW, Shallice T. Response suppression, initiation and strategy use following frontal lobe lesions. Neuropsychologia. 1996;34(4):263-72. https:// doi.org/10.1016/0028-3932(95)00104-2.

5. Bielak AA, Mansueti L, Strauss E, Dixon RA. Performance on the hayling and brixton tests in older adults: norms and correlates. Arch Clin Neuropsychol. 2006;21(2):141-9. https://doi.org/10.1016/j.acn.2005.08.006.

6. Pérez-Pérez, Alicia, Matias-Guiu, Jordi A, Cáceres-Guillén, Iris, Rognoni, Teresa, Valles-Salgado, María, Fernández-Matarrubia, Marta, .. . Matías-Guiu, Jorge. (2016). The hayling test: development and normalization of the spanish version. Arch Clin Neuropsychol, 31(5), 411-419.

7. Spitoni GF, Bevacqua S, Cerini C, Ciurli P, Piccardi L, Guariglia P, et al. Normative data for the hayling and brixton tests in an italian population. Arch Clin Neuropsychol. 2018;33(4):466-76. https://doi.org/10.1093/arclin/ acx072.

8. Vestberg S, Nordstrom EB, Waldo ML, Nilsson K, Santillo AF, Nilsson C. Swedish version of the hayling test: clinical utility in frontotemporal dementia syndromes. J Int Neuropsychol Soc. 2019;25(2):195-203. https:// doi.org/10.1017/S1355617718001030.

9. Cervera-Crespo T, Gonzalez-Alvarez J. Age and semantic inhibition measured by the hayling task: a meta-analysis. Arch Clin Neuropsychol. 2017;32(2):198-214. https://doi.org/10.1093/arclin/acw088.

10. Hackman DA, Gallop R, Evans GW, Farah MJ. Socioeconomic status and executive function: developmental trajectories and mediation. Dev Sci. 2015; 18(5):686-702. https://doi.org/10.1111/desc.12246.

11. Quinteros Baumgart C, Billick SB. Positive cognitive effects of bilingualism and multilingualism on cerebral function: a review. Psychiatr Q. 2018;89(2): 273-83. https://doi.org/10.1007/s11126-017-9532-9.

12. Cohen JF, Gorski MT, Gruber SA, Kurdziel LB, Rimm EB. The effect of healthy dietary consumption on executive cognitive functioning in children and adolescents: a systematic review. Br J Nutr. 2016;116(6):989-1000. https:// doi.org/10.1017/S0007114516002877.
13. Yang Y, Shields GS, Guo C, Liu Y. Executive function performance in obesity and overweight individuals: a meta-analysis and review. Neurosci Biobehav Rev. 2018;84:225-44. https://doi.org/10.1016/j.neubiorev.2017.11.020.

14. Berryman N, Bherer L, Nadeau S, Lauziere S, Lehr L, Bobeuf F, et al. Executive functions, physical fitness and mobility in well-functioning older adults. Exp Gerontol. 2013;48(12):1402-9. https://doi.org/10.1016/j.exger. 2013.08.017.

15. Tzivian, L., Dlugaj, M., Winkler, A., Hennig, F., Fuks, K., Sugiri, D.,. .. Heinz Nixdorf Recall Study Investigative, Group. (2016). Long-term air pollution and traffic noise exposures and cognitive function: a cross-sectional analysis of the heinz nixdorf recall study. J Toxicol Environ Health A, 79(22-23), 1057-1069. doi: https://doi.org/10.1080/15287394.2016.1219570.

16. Ng TP, Lim ML, Niti M, Collinson S. Long-term digital mobile phone use and cognitive decline in the elderly. Bioelectromagnetics. 2012a;33(2):176-85. https://doi.org/10.1002/bem.20698

17. Besset A, Espa F, Dauvilliers Y, Billiard M, de Seze R. No effect on cognitive function from daily mobile phone use. Bioelectromagnetics. 2005;26(2):1028. https://doi.org/10.1002/bem.20053.

18. Hayashi Y, Rivera EA, Modico JG, Foreman AM, Wirth O. Texting while driving, executive function, and impulsivity in college students. Accid Anal Prev. 2017;102:72-80. https://doi.org/10.1016/j.aap.2017.02.016.

19. Akter S, Hassan MR, Shahriar M, Akter N, Abbas MG, Bhuiyan MA. Cognitive impact after short-term exposure to different proton pump inhibitors: assessment using cantab software. Alzheimers Res Ther. 2015;7:79. https:// doi.org/10.1186/s13195-015-0164-8.

20. Ho JK, Nation DA. Memory is preserved in older adults taking at1 receptor blockers. Alzheimers Res Ther. 2017:9(1):33.

21. Group, VITAL Trial Collaborative. Effect of vitamins and aspirin on markers of platelet activation, oxidative stress and homocysteine in people at high risk of dementia. J Intern Med. 2003;254(1):67-75.

22. Cervera, Crespo Teresa, González, Álvarez Julio, \& Rosell, Clari Vicente. (2019) Semantic inhibition and dementia severity in alzheimer's disease.

23. Martyr A, Boycheva E, Kudlicka A. Assessing inhibitory control in early-stage alzheimer's and parkinson's disease using the hayling sentence completion test. J Neuropsychol. 2019;13(1):67-81.

24. Ramanan S, Bertoux M, Flanagan E, Irish M, Piguet O, Hodges JR, Hornberger M. Longitudinal executive function and episodic memory profiles in behavioral-variant frontotemporal dementia and alzheimer's disease. J Int Neuropsychol Soc. 2017;23(1):34-43. https://doi.org/10.1017/ S1355617716000837.

25. Rabinowitz AR, Levin HS. Cognitive sequelae of traumatic brain injury. Psychiatr Clin North Am. 2014;37(1):1-11. https://doi.org/10.1016/j.psc.2013. 11.004 .

26. Povroznik JM, Ozga JE, Haar CV, Engler-Chiurazzi EB. Executive (dys) function after stroke: special considerations for behavioral pharmacology. Behav Pharmacol. 2018;29(7):638-53.

27. Obeso I, Wilkinson L, Casabona E, Bringas ML, Alvarez M, Alvarez L, et al. Deficits in inhibitory control and conflict resolution on cognitive and motor tasks in parkinson's disease. Exp Brain Res. 2011;212(3):371-84. https://doi. org/10.1007/s00221-011-2736-6.

28. Matías-Guiu JA, Cabrera-Martín MN, Valles-Salgado M, Rognoni T, Galán L, Moreno-Ramos T, et al. Inhibition impairment in frontotemporal dementia, amyotrophic lateral sclerosis, and alzheimer's disease: clinical assessment and metabolic correlates. Brain Imaging Behav. 2019;13(3):651-9.

29. Giraldo-Chica M, Rogers BP, Damon SM, Landman BA, Woodward ND. Prefrontal-thalamic anatomical connectivity and executive cognitive function in schizophrenia. Biol Psychiatry. 2018;83(6):509-17. https://doi.org/ 10.1016/j.biopsych.2017.09.022

30. Lima IMM, Peckham AD, Johnson SL. Cognitive deficits in bipolar disorders: implications for emotion. Clin Psychol Rev. 2018;59:126-36. https://doi.org/ 10.1016/j.cpr.2017.11.006

31. Demetriou EA, Lampit A, Quintana DS, Naismith SL, Song YJC, Pye JE, et al. Autism spectrum disorders: a meta-analysis of executive function. Mol Psychiatry. 2018;23(5):1198-204. https://doi.org/10.1038/ mp.2017.75.

32. Ronnlund M, Nyberg L, Backman L, Nilsson LG. Stability, growth, and decline in adult life span development of declarative memory: cross-sectional and longitudinal data from a population-based study. Psychol Aging. 2005;20(1): 3-18. https://doi.org/10.1037/0882-7974.20.1.3.

33. Bernier PJ, Gourdeau C, Carmichael PH, Beauchemin JP, Verreault R, Bouchard RW, et al. Validation and diagnostic accuracy of predictive curves 
for age-associated longitudinal cognitive decline in older adults. CMAJ. 2017;189(48):E1472-80. https://doi.org/10.1503/cmaj.160792.

34. Comrey AL, Lee HB. A first course in factor analysis. United Kingdom: Psychology press; 2013.

35. Lung, National Heart, \& Institute, Blood. Your guide to lowering your blood pressure with dash. Bethesda: U.S. DEPARTMENT OF HEALTH AND HUMAN SERVICES (National Institutes of Health National Heart, Lung, and Blood Institute); 2006. Available from: https://www.nhlbi.nih.gov/files/docs/public/ heart/new_dash.pdf.

36. Hagströmer M, Oja P, Sjöström M. The international physical activity questionnaire (ipaq): a study of concurrent and construct validity. Public Health Nutr. 2006;9(6):755-62.

37. Lopez-Fernandez O, Kuss DJ, Pontes HM, Griffiths MD, Dawes C, Justice LV, et al. Measurement invariance of the short version of the problematic mobile phone use questionnaire (pmpuq-sv) across eight lanquages. Int $J$ Environ Res Public Health. 2018;15(6). https://doi.org/10.3390/ ijerph15061213.

38. Marsh HW, Hau K-T, Wen Z. In search of golden rules: comment on hypothesis-testing approaches to setting cutoff values for fit indexes and dangers in overgeneralizing hu and bentler's (1999) findings. Struct Equ Model. 2004;11(3):320-41.

39. Sage C, Burgio E. Electromagnetic fields, pulsed radiofrequency radiation, and epigenetics: how wireless technologies may affect childhood development. Child Dev. 2018;89(1):129-36. https://doi.org/10.1111/cdev.12824.

40. Arns M, Van Luijtelaar $G$, Sumich A, Hamilton R, Gordon E. Electroencephalographic, personality, and executive function measures associated with frequent mobile phone use. Int J Neurosci. 2007;117(9): 1341-60. https://doi.org/10.1080/00207450600936882.

41. Savulich G, Hezemans FH, van Ghesel Grothe S, Dafflon J, Schulten N, Bruh $A B$, et al. Acute anxiety and autonomic arousal induced by $\mathrm{CO} 2$ inhalation impairs prefrontal executive functions in healthy humans. Transl Psychiatry. 2019;9(1):296. https://doi.org/10.1038/s41398-019-0634-z.

42. Siponen T, Yli-Tuomi T, Tiittanen P, Taimisto P, Pekkanen J, Salonen RO, Lanki T. Wood stove use and other determinants of personal and indoor exposures to particulate air pollution and ozone among elderly persons in a northern suburb. Indoor Air. 2019;29(3):413-22.

43. Herren OM, Burris SE, Levy SA, Kirk K, Banks KS, Jones VL, et al. Influence of spirituality on depression-induced inflammation and executive functioning in a community sample of african americans. Ethn Dis. 2019;29(2):267-76. https://doi.org/10.18865/ed.29.2.267

44. Paseban M, Mohebbati R, Niazmand S, Sathyapalan T, Sahebkar A. Comparison of the neuroprotective effects of aspirin, atorvastatin, captopril and metformin in diabetes mellitus. Biomolecules. 2019;9(4). https://doi.org/ 10.3390/biom9040118

\section{Publisher's Note}

Springer Nature remains neutral with regard to jurisdictional claims in published maps and institutional affiliations.

Ready to submit your research? Choose BMC and benefit from:

- fast, convenient online submission

- thorough peer review by experienced researchers in your field

- rapid publication on acceptance

- support for research data, including large and complex data types

- gold Open Access which fosters wider collaboration and increased citations

- maximum visibility for your research: over $100 \mathrm{M}$ website views per year

At $\mathrm{BMC}$, research is always in progress.

Learn more biomedcentral.com/submissions 